\title{
Could robots strengthen the sense of autonomy of older people residing in assisted living facilities? - A future-oriented study
}

\author{
Jari Pirhonen $^{1}$ (D) $\cdot$ Helinä Melkas ${ }^{2}$ D $\cdot$ Arto Laitinen $^{3}$ (D) Satu Pekkarinen ${ }^{2}$ (D
}

Published online: 26 December 2019

(c) The Author(s) 2019

\begin{abstract}
There is an urge to introduce high technology and robotics in care settings. Assisted living (AL) is the fastest growing form of older adults' long-term care. Resident autonomy has become the watchword for good care. This article sheds light on the potential effects of care robotics on the sense of autonomy of older people in AL. Three aspects of the residents' sense of autonomy are of particular interest: (a) interaction-based sense of autonomy, (b) coping-based sense of autonomy, and (c) potential-based sense of autonomy. Ethnographical data on resident autonomy in an AL facility and existing literature on care robots are utilized in studying what kind of assurances different types of robots would provide to maintain the sense of autonomy in AL. Robots could strengthen the different types of sense of autonomy in multiple ways. Different types of robots could widen the residents' space of daily movements, sustain their capacities, and help them maintain and even create future expectations. Robots may strengthen the sense of autonomy of older persons in AL; however, they may simultaneously pose a threat. Multi-professional discussions are needed on whether robots are welcomed in care, and if they are, how, for whom, and in what areas.
\end{abstract}

Keywords Care robots $\cdot$ Assisted living $\cdot$ Sense of autonomy $\cdot$ Older people

\section{Introduction}

There are two major trends in Western long-term care for older people today. The first concerns the substance and quality of care, in which the keywords have become individuality (Brooker 2004; Brownie and Nancarrow 2013) and autonomy (Agich 2003; Christman 2014; Lidz et al. 1992). Therefore, different forms of assisted living (AL) facilities have replaced traditional and medical nursing homes and become the fastest growing form of long-term care for the older adults in extensive need of help (Ball et al. 2004; Street et al. 2007; Zimmerman et al. 2003). There is no exact

Jari Pirhonen

jari.pirhonen@tuni.fi

1 Faculty of Social Sciences and Gerontology Research Center, Tampere University, P.O. Box 100, 33014 Tampere, Finland

2 School of Engineering Science, Lappeenranta-Lahti University of Technology LUT, Saimaankatu 11, 15140 Lahti, Finland

3 Faculty of Social Sciences, Tampere University, P.O. Box 100, 33014 Tampere, Finland definition for AL; in the United States, for example, these facilities are known by about 20 different names (Mitchell and Kemp 2000). However, the core idea of AL is to dissolve the institutional characteristics of a care facility. AL has been seen to emphasize a home-like environment that fosters respect for an individual's sense of autonomy, privacy, and freedom of choice (Roth and Eckert 2011).

The second major trend is the urge to introduce high technology and robotics in care for the older persons, emanating from the rapidly growing number of very old people (Bedaf et al. 2015; Kachouie et al. 2014; Robertson 2007; Turja et al. 2017). Demographic transition in Western societies has resulted in deteriorating maintenance ratios and austerity in public social and health care services (Christensen et al. 2009; Giannakouris 2008). At the same time, underpaid and overloaded care work does not lure young people (Turja et al. 2017). Therefore, technology, especially robotics, has been pictured as one solution to this problem.

Robots are programmable machines that can move and perform tasks in their environment independently or semiindependently (Goeldner et al. 2015; Turja et al. 2017). By definition, robots interact with their environment and thus manipulate it (Sparrow and Sparrow 2006). Although 
telepresence robots do not function autonomously but instead require a remote user to operate them, we include them in this study. Through the telepresence technology, the operator can virtually see into another space through a two-way camera and can operate the robot via software on their computer. The operator can, therefore, feel physically present at the location of the robot irrespective of where the robot is located (Moyle et al. 2014; Niemelä et al. 2019).

Care robots are a subcategory of service robots, developed to assist either nursing staff or patients or both in care environments (van Wynsberghe 2013). These devices do not necessarily interact with people in care surroundings but may also perform logistic or surveillance tasks. Care robotics, then, is not a category defined according to robots' capabilities but rather the environment in which they are implemented.

Both the rapid increase of AL and the urge to develop care robots have deep financial, societal, demographic, and medical roots. The outspoken idea of $\mathrm{AL}$ is to provide a choice of services and lifestyles to avoid the typical characteristics of an institutional setting (Zimmerman et al. 2005), emphasizing improvement in the quality of life as the primus motor of development. There are, however, economic drivers behind the phenomenon. According to Chapin and Dobbs-Keppler (2001), AL is perceived as an economical way to care for low-income, frail older people compared to care given in medical nursing homes. For example, staffing ratios are lower in AL than in nursing homes (Dick 2014). Other societal forces that favor the triumphal march of AL are market-friendly social-policy doctrines and demands to develop user-friendly service systems that enable freedom of choice. Even in the Nordic countries, where the welfare state has traditionally been strong, marketization of elderly care services has been rapid, resulting in an increase of AL supported by private enterprises (Anttonen and Häikiö 2011).

Regarding the urge to develop and later on implement care robotics, financial and societal drivers are even more straightforward. Starting in Japan in the 1990s and adopted by Western societies, care robotics has been pictured as a necessity in future elderly care, cutting costs and compensating for the absence of human hands (Robertson 2007). However, the use of care robots is still mostly taking its first steps, even in Japan. There is a growing amount of literature on the possibilities of care robotics to improve the quality of life in old age (e.g., Mitzner et al. 2014; Robinson et al. 2014; Smarr et al. 2014) and ethical questions about robots in care (Sharkey and Sharkey 2011, 2012; Turkle 2011; Vandemeulebroucke et al. 2017a). However, in order to broaden the views about care robotics as a positive resource in elderly care-away from being purely a response to economic pressures-more research on robotics' implications for the lives of older people is needed now and in future.

\section{Nature of residents' autonomy in AL}

Patient autonomy, and in this case resident autonomy, has become the watchword for good care throughout the Western world. According to Morgan and Yoder (2012), Institute of Medicine in the United States defines good care as care that is respectful and responsive to individual patient preferences, needs, and values, and ensures that patients' values guide all clinical decisions. In Canada, the philosophy of assisted living is to provide housing with supports that enable tenants to maintain an optimal level of independence (Government of British Columbia 2018). The Finnish Ministry of Social Affairs and Health (2018) also emphasizes autonomy and self-determination as marks of high-quality services for older persons. Furthermore, the Ministry mentions that for using robotics, automation, and new technologies, the starting point should be supporting and expanding an older person's right to self-determination and independence, improved service, and developing and supporting the staff's work (Ministry of Social Affairs and Health 2018).

However, there is a difference between the ideal and the reality in AL. After all, individuals need long-term care because they suffer from illnesses and incapacities that compromise their ability to function independently and make rational life choices (Agich 2003). Furthermore, being influenced by policies emphasizing home care as a primary form of care for older people, they enter AL in an ever weaker condition than before (Dick 2014), which inevitably affects their chances to act autonomously. Besides, residents' autonomy may also be lessened by paternalistic attitudes from the staff and by the interests and wishes of other people, for example relatives (Sherwin and Winsby 2010). Collopy (1988) holds that helping interventions may be influenced by the motivations of the helpers instead of the helped, and daily routines of a facility are yet another matter that influence residents' autonomy (Eyers et al. 2012; Pirhonen 2017; Pirhonen and Pietilä 2016).

The concept of relational autonomy (Atkins 2006; Christman 2014; MacKenzie and Stoljar 2000; Pirhonen and Pietilä 2016; Sherwin and Winsby 2010) would fit AL residents' situation better, since it takes into account that individuals' actions are inevitably connected to multiple relational factors, such as social relationships, personal characteristics, and the chances and restrictions of the agent's environment. Prior research indicates that autonomy in AL is constant balancing between independence and dependence (Ball et al. 2004) and adjusting to changes in the older persons' restrictive functional abilities (Morgan et al. 2014). The concept of relational autonomy indicates that autonomy is not an all-or-nothing 
matter. There are degrees in it, and autonomy also has a strong psychological aspect-one needs to have a sense of autonomy, despite her/his factual situation. The sense of autonomy refers to people's lived feelings and assessments concerning their degree of autonomy-even when factual capacities to live a self-governed life deteriorate, it is possible that the sense of autonomy does not drop to the same degree.

Previous research has shown that older people maintain their sense of autonomy in various ways, despite the issues listed above that restrict autonomy (Ball et al. 2004; Freund and Baltes 1998; Kontos 2004, 2005; Pirhonen 2017). Regarding care robotics and older people's sense of autonomy, we found three previously formed aspects of residents' sense of autonomy to be of particular interest: (a) the influence of other people, (b) the level of a person's remaining functional abilities linked to coping strategies, and (c) the potentials to act (Pirhonen 2017; cf. Freund and Baltes 1998). These aspects were introduced by the first author in his prior ethnographical study on resident autonomy (Pirhonen 2017): they were categorized from the residents' reflections about their autonomy. In this paper, we include robotics and focus more precisely on the sense of autonomy, which need not co-vary with the real degree of autonomy. Even when one's capacities begin to lower, these three ways of sustaining one's sense of autonomy may explain if one's sense of autonomy remains high. The rationale behind the three views on autonomy is as follows:

(i) When one's functional capacity deteriorates in old age, help from relatives and friends has been found to result in a sense of autonomy, described as not being much dependent on formal care system (anonymized for review). Paradoxically, then, received help may strengthen one's sense of autonomy (cf. Lloyd et al. 2014). One theoretical basis for this can be the way in which recognition from others (respect, esteem, and love) supports positive self-relations (self-respect, self-esteem, and self-concern), which in turn are necessary for effective agency in social contexts: total lack of self-respect, self-esteem, or self-concern may "paralyze" a person (Anderson and Honneth 2005). In this article, we call this phenomenon an interaction-based sense of autonomy.

(ii) Residents' remaining functional abilities have been found to reinforce their possibilities to act autonomously. It is not a one-way street, however. Restrictive abilities do not automatically result in a lesser sense of autonomy since residents compensate for the loss of functional abilities through different coping strategies (Pirhonen 2017; cf. Freund and Baltes 1998). In the first author's prior study (Pirhonen 2017), residents utilized aids, chose more manage- able tasks, lowered the standards of perceiving things as autonomous, and compared their situation to peers with lower levels of functional capacity. Utilizing different strategies to cope with restrictive functional abilities is referred to as a coping-based sense of autonomy.

(iii) Pirhonen (2017) found that residents who were losing their functional abilities shifted the emphasis from acting to potentials to act. They emphasized things they could have done if they wanted to, yet they postponed the actualization of doings into the uncertain future. At the same time, they expressed hope that their functional abilities to accomplish desired matters would remain in the future. Hope has been pictured as a critical factor in residents' ability to maintain their sense of autonomy in AL settings (Perkins et al. 2012). Emphasizing potentials to act is referred to as a potential-based sense of autonomy.

Of these, the (i) interaction-based sense of autonomy is closely related to relational autonomy: availability of other people may help sustain one's sense of autonomy even when one's functional capacities deteriorate. (ii) The coping strategies are another way to sustain one's sense of autonomy in such a situation of lowering capacities. In subsequent parts, we will be looking into the relevance of these strategies. A third mechanism which helps sustain one's sense of autonomy is (iii) the change of focus to potential instead of actual acting (which could perhaps be seen as one additional coping strategy, but we here follow Pirhonen (2017) in discussing these as three aspects).

In this paper, we will analyze the potential effects of care robots on the residents' sense of autonomy concerning the three aspects introduced above: interaction-, coping-, and potential-based sense of autonomy. Based on prior ethnographical data on resident autonomy, gathered by the first author in an AL facility (Pirhonen 2017), and reflecting on it in light of the existing literature on care robots, we ask what kind of assurances would different types of robots provide to maintain the sense of autonomy of older people residing in AL. We also inquire what kinds of threats would robotization of care pose in the future regarding this issue. The article does not reflect on residents' views on robots, but is a future-oriented theoretical study drawing on ethnographical data on the autonomy of AL residents on the one hand and prior literature on care robots on the other. 


\section{Empirical data and analysis}

\section{The research setting and sample}

The first author collected empirical data by undertaking participant observation and conducting thematic interviews at a single care facility for older people in Southern Finland in 2013-2014. The research site was an AL facility where 114 residents lived in eight group homes, with 9 to 15 residents in each home. The idea was to provide as homelike an environment for the residents as possible. People had their own rooms that they had furnished with their personal belongings and wore their own clothes rather than clothes provided by the AL facility. In addition to residential rooms, there were common rooms, large balconies, and a sauna in every group home. Staff members were available around the clock. Most of the residents had some degree of cognitive disorders; some were there for somatic or physical reasons, and some were suffering from both cognitive and physical illnesses (Pirhonen 2017).

There were no actual care robots in the facility. However, the staff used lifting devices to move residents with the weakest physical abilities (e.g., from their bed to a wheelchair). The residents wore wristwatches that also acted as safety equipment. The watch had a button that could be used to alarm the staff; they would then visit the resident in her/his room or call them by phone. The call would come through a device in a wall in the residents' rooms, so residents did not have to move physically to answer the call. Watches also contained bulbs that recorded the residents' physical activity; nonetheless, the research data showed no evidence of staff utilizing the surveillance option. Cameras were used to monitor common spaces but not the residents' rooms. The residents used wheelchairs and walkers to move around. Some used audio books or different kinds of magnifying glasses due to poor eyesight. Only one resident had a laptop and an Internet connection (Pirhonen 2017).

\section{The data collection}

At first, life at the facility was observed for $165 \mathrm{~h}$ over 2 months. The researcher participated in everyday life in the same way as a volunteer worker would do: socializing with the residents, taking them outside, helping them eat, and helping the staff when necessary (in tasks which did not require professional training). The researcher also interacted with the staff and the residents' family members and friends. He took notes on paper in the field and transcribed them on the computer immediately after the observations. The final observational data included 79 pages of text.
After the observation period, 10 thematic interviews were conducted with the residents. The staff was asked to indicate the 10 residents cognitively fit enough to give an interview and an informed consent to participate. Themes were organized around the residents' backgrounds (education, work-life balance, family ties, etc.), the facility as a living environment, the care received, the content of residents' daily lives, and their perceptions of their life situation in general. There were no questions about robot use in care, but for the purpose of this paper, the researchers reflected on these issues based on residents' autonomy-related talk. The interviews were recorded and lasted 25-65 min and were then transcribed verbatim, totaling 281 pages. The ethical committee of the local hospital district gave ethical approval for the research (Pirhonen 2017).

\section{The data analysis}

The first phase of analysis was carried out by the first author. He first separated all the data components that contained the residents' sense of autonomy (i.e., their will, wishes, or preferences). For example, the residents talked about their wishes and the factors that prevented them from fulfilling them, such as "I would like to go out more often but I don't think the staff has time for that." The observational data, on the other hand, provided indications that other people or the setting itself seemed to constrain the residents' actions, such as a locked door that prevented a resident with a cognitive disorder from going out.

In the second phase, the data were categorized under three domains: (a) interaction with other people, (b) coping with age-based functional losses, and (c) future expectations and potentials to act. These domains were brought from the first author's prior work on autonomy in AL (Pirhonen 2017). In the third phase, a philosopher and two technology researchers were brought into the research to strengthen the analysis with their expertise on autonomy and prior literature on care robots. At the same time, triangulation (Thurmond 2001) was achieved through the use of two kinds of empirical data and the engagement of several researchers. The diverse composition of researchers allowed us to analyze what kinds of robots could possibly have had positive effects on the residents' autonomy and in what ways. Thus, the analysis was theory-directed (Hsieh and Shannon 2005), combining empirical research data with prior knowledge on care robots (e.g., Bedaf et al. 2015; Kachouie et al. 2014; Robinson et al. 2014; Vandemeulebroucke et al. 2017a, b). In the next section, we will analyze the potential effects of care robots on the residents' autonomy. All the names mentioned in the text are pseudonyms. 


\section{Future promises and threats of robots on residents' sense of autonomy}

\section{Interaction-based sense of autonomy}

The residents in AL spoke about how their relatives and friends living outside the facility brought goods and items they needed and took them out for a walk or to run errands. This was appreciated since the facility had provided the residents with a hospital bed and bedside table, food, medicine, and toiletries but not with all the little conveniences that the residents needed, such as goodies, cigarettes, alcohol, magazines, etc. The staff was also too busy with making beds and taking care of the residents to be able to take them outdoor, so friends and family members took them for walks. As noted in the introduction, help from relatives and friends may strengthen the residents' sense of autonomy by lessening their dependence on formal care (Lloyd et al. 2014; Pirhonen and Pietilä 2016).

How, then, could robots help to maintain an interactionbased sense of autonomy in residential care? We classify the use of technological aids as one of the coping strategies; the technological aids can directly boost the residents' abilities and the coping-based sense of autonomy (see the next subsection). For example, there is a potential for logistic robots that can distribute goods autonomously to different places (see Hennala et al. 2017). There was a cafeteria in the local area and, had there been a logistic robot delivering objects between places, it could have brought the residents goodies when they wanted them. At the moment, logistic robots are in professional use in big hospitals and distribution centers; however, they have the potential to serve individual older persons in the future (Benzidia et al. 2018), decreasing the feeling of being dependent on nursing staff.

Indirectly such technological aids can also facilitate the interaction-based sense of autonomy. Helping people to move around with robot assistance offers great potential in strengthening their interaction-based sense of autonomy. For instance, in the future, exoskeletons may help people with physical disadvantages to move around and thus help them maintain their social lives outside the facility. An important part of informal social life is the experience of being able to rely on help from others, and these experiences are vital for the interaction-based sense of autonomy. A technological aid that directly helps one move, also indirectly facilitates opportunities to be helped by others.

Exoskeletons, as assistive devices, are external structural mechanisms with joints and links corresponding to those of the human body. A powered exoskeleton is a powered mobile machine consisting of an exoskeleton-like framework worn by a person and a power supply for the activation energy for limb movement (Sale et al. 2012). Alternatively, if the staff used exoskeletons, they would be able to lift the residents more easily and frequently out of their bed into the wheelchair, if it took less time and effort. Either way, the residents could enjoy better social interactions outside their rooms and the facility.

On the other hand, exoskeletons are costly devices, making them inaccessible to many individuals (even organizations). In addition to exoskeletons, robot wheelchairs and walkers are being tested all over the world and may help people with lower functional abilities move around more easily in the near future (e.g., Goher 2016; Shiomi et al. 2015; Werner et al. 2018), enabling the user to shift from sitto-stand posture, for example (Goher 2016). Also, humanoid robots as walking partners have been tested in Japan with promising results for widespread acceptance (Karunarathne et al. 2018). A humanoid robot walks side by side a human being and provides company when walking and motivates people to exercise. This kind of equipment would lessen the residents' dependence on nursing staff and thus could have a positive impact on their interaction-based sense of autonomy, when informal helping behavior would increase thanks to increased mobility. Exoskeletons could provide fragile older people an increased ability to move freely (bodily integrity) and participate in social interaction or access experiences such as religious, literary or musical events. However, it might affect a person's feeling of dignity, if a robot moved the person without her permission or in a humiliating way like she were an object. (Sharkey 2014.)

A telepresence robot is a potential helper in socioemotional support, assuming the resident has someone outside the facility with whom she/he can interact. In recent years, several pilot studies on telepresence robots in elderly care have been conducted (e.g., Aaltonen et al. 2017; Cesta et al. 2016; Koceski and Koceska 2016; Niemelä et al. 2019). With telepresence technologies, a sense of physical presence in a remote place can be created. Cesta et al. (2016), for instance, noted that a telepresence robot had a significantly positive impact on the sense of independence and adequacy in daily life. Telepresence robots and other accessible communication devices could strengthen the residents' contacts with the outside and thus might reinforce their interactionbased sense of autonomy, while again being less dependent on the nursing staff. Even people with no technical skills would benefit from a robot that could make a video call to people outside via voice command. For the lonely individuals, this would be a way to organize a network of volunteers or other people with whom to communicate. Video calls have been found to reduce older people's loneliness in care environments (Zamir et al. 2018). Many residents who are incapable of moving around by themselves tend to spend most of their days alone in their rooms (Pirhonen 2017; Pirhonen and Pietilä 2016). Telepresence robots have 
the potential to bring people outside the facility closer to those inside it. A threat, however, is that a lonely person is left to feel even lonelier in the facility, communicating mainly via the virtual connection (Vandemeulebroucke et al. 2017b). The connection is not entirely similar to a face-toface encounter; however, if it helps a person and offers her/ him socioemotional support, there is some promising potential. It has often been highlighted that technology should not be taken as a substitute for human contacts and care (e.g. Sharkey 2014); nonetheless, it can help ensure a more effective and intensive way of communication (Cesta et al. 2016; Pekkarinen et al. 2013; Pekkarinen and Melkas 2017).

These kinds of monitoring robots can be seen to increase people's ability to have good health, or to move freely from one place to another or to feel safe against violent assault. These could also offer the possibility of increased communication (access to internet or various forms of social interaction) or to be informed and cultivated, and produce works or events of one's own choice (Sharkey 2014). In addition, virtual care can be offered with the help of robots, and related to sense of autonomy, the users' may feel that they lose the responsibility for monitoring their own wellbeing themselves, or patronized by constant reminders and health advice. (Garner et al. 2016). Intrusive monitoring could, in general, be an unpleasant experience for the recipient (Sharkey 2014).

Interaction with a person who has severe dementia is another matter. Some comforting support could be provided using a therapeutic robot, such as Paro-a seal-like robot-or JustoCat. When interacting with other people has become very difficult, other ways such as touching may be of greater importance (Bush 2001). The continuous use of Paro has shown that the robot can encourage elderly residents to communicate with each other (Wada and Shibata 2007; Cesta et al. 2016). Music might also be helpful—new, perhaps robotic, solutions could be developed to this end. Concerning JustoCat, Gustafsson et al. (2015) found that its use led to positive effects by providing increased interaction, communication, stimulation, relaxation, peace, and comfort to individuals with dementia. This is similar to a phenomenon that Sorell and Draper (2014) called presence. Presence here is the kind of co-location of a device with a person that brings it about that the person no longer feels alone. Human or animal shaped robots' presence might sometimes solely be enough to calm residents in AL. Companion robots can thus maintain a person's sense of autonomy in an indirect way; through supporting social connections and providing 'light' companionship - to reduce loneliness, isolation, anxiety and depression, which typically amount to a reduced sense of interaction-based autonomy. Reduced loneliness, isolation, anxiety, and depression thus may have as its flipside a heightened interaction-based sense of autonomy (Niemelä and Melkas 2019; Roger et al. 2012).

\section{Coping-based sense of autonomy}

The residents may cope with the restrictive functional abilities by (a) lowering the standards of autonomy, (b) choosing doings that better fitted their hampering abilities, (c) using aids, and (d) comparing their situation with peers who have poorer functional abilities (Pirhonen 2017; Pirhonen and Pietilä 2016). In this subsection, these ways of coping will be examined separately.

\section{Lowering the standards of autonomy}

The individual's coping mechanism of lowering the standards of autonomy can be seen as an attempt to adjust to the situation: once one recognizes that the range of options is limited, she/he cannot enjoy full autonomy, unless the goalposts are shifted. Once the goalposts are shifted, or the standards lowered, the limited range of actions does not entail a lower degree of autonomy. In other words, it is still genuine autonomy, albeit based on a lower degree of functionings. Lowering standards is a significant way to maintain one's sense of autonomy. Robots could postpone the need to lower the standards of being autonomous in this way, by maintaining the ability to function, with the help of technological aids. Helena had lost the ability to move her legs due to a somatic illness, and she needed the staff to help her out of bed and into her wheelchair. When she was asked if she was able to move freely with the wheelchair in the facility, she answered in the affirmative. She then said that she could wheel herself from the dining room to the door of her room, where she waited for a nurse to let her in. Thus, she had lowered the standards of being autonomous-it was autonomous enough to be able to wheel the chair in the first place. A robot could potentially help Helena move longer distances and enter her room without any help from the staff so that there would not have been a need for her to lower the standards. On the other hand, a walking robot providing support for physiotherapy might be able to provide appropriate rehabilitation for Helena, leading to some improvement in moving her legs. Even small improvements may have a significant impact on a person's life and her/his sense of autonomy. Exoskeletons might also be an option in this case. Robots may thus function in compensatory roles, but hopefully increasingly in roles that help in maintaining positive things that may then enable other positive things and so forth. They may enable the residents to cope by other means, leaving the strategy of lowering the standards of autonomy for later dates (when the capacities have possibly lowered even further). However, it also has to be noted that the provision of exoskeletons to vulnerable older people who are unable to use them safely may also pose risks to their own or other people's health (Sharkey 2014). 


\section{Selecting appropriate doings}

It has been argued that, for full autonomy, one needs a sufficient range of meaningful options-meaningful goals for action from which to choose ( $\operatorname{Raz} 1986)$. That some goals turn out to be impossible for one does not yet reduce the person's autonomy at all, as long as one has a sufficient range of meaningful options. And if one already has a sufficient range of meaningful options, adding more to them will not add to her/his autonomy. However, when the range of options is reduced further, at some point the person's degree of autonomy will consequently be lowered. Nonetheless, autonomy is not an all-or-nothing matter, so in choosing goals from within the available options, in virtue of the level of one's capabilities, one may still enjoy some degree of autonomy. Similarly, people may differ in the range of options they would require to maintain their subjective sense of autonomy. Due to her aching wrists, Helena, for example, had switched from crocheting to doing crosswords. Because of the shortness of breath, Leo had changed from walking outside to sitting on a bench. Changing from one meaningful option to another is a way of retaining one's sense of autonomy. There are two ways in which robotic developments could be relevant here. First, by retaining the capacities via technological aids is, again, relevant. Although it is currently unfeasible that a robot could help Helena continue crocheting (although it may be possible in the future), robot wheelchairs that could help Leo move around outdoors are already being designed. Secondly, there could be new kinds of activities, made possible by technology, that Leo and Helena still could be capable of doing, and could switch to when doing crosswords or sitting on a bench become too challenging.

\section{Using aids}

As we have seen, using aids may be more useful than resorting to coping mechanisms to maintain one's sense of autonomy: the use of aids can sustain full autonomy and postpone the need for adjusting one's goals or expectations of the level of autonomy one can enjoy. Nonetheless, even when a person's degree of autonomy begins to drop, various aids can help in slowing its progress toward deterioration. In our data, the residents used walkers and wheelchairs to move around; due to poor eyesight, some used audio books. Robots could be seen as high-tech aids to older people. Daily routine activities such as bathing, dressing, toileting, and transfer (often a component of toileting) appear to require considerable assistance to perform, especially when high levels of care are needed. To be able to perform these activities, being closely linked to a person's autonomy, assistive devices have been developed, although they have not been universally adopted. For example, "Poseidon"—a shower robot - has received extensive positive reviews; however, its use has remained limited. Assistance with toileting, in particular, is a critical need of older adults living in long-term care residences (Mitzner et al. 2014); however, this may also be the concern of those living at home, possibly cared for by a spouse or relative. Given the importance of these issues for a person's autonomy as well as physical and mental wellbeing, they require urgent attention in the field of robotics (e.g., Mitzner et al. 2014). Care robots are being designed and implemented all over the world for both professional (e.g., surgery) and domestic purposes. For example, CareO-bot 4, designed in Germany, is being studied in Finland (https://roseproject.aalto.fi/en/). The manufacturer states that Care-O-bot "is the product vision of a mobile robot assistant to actively support humans in domestic environments. The fourth generation of this successful development series is more agile and modular than its predecessors and offers various ways of interaction." (https://www.care-o-bot. de/en/care-o-bot-4.html). Since assistive robots today are usually designed to be socially assistive, the manufacturer states that "while the concept for the Care-O-bot 3 was a more reserved, cautious butler, its successor is as courteous, friendly, and affable as a gentleman." (https://www. care-o-bot.de/en/care-o-bot-4.html). It is possible to install arms onto a Care-O-bot 4, which makes it handy for people with a limited ability to move independently. It also interacts socially with people, and future versions of it will probably have more useful properties.

Future robots may be important aids for older persons who are cognitively fit to utilize them. After all, the downside of such robots is that they are costly and hence only available for wealthy people; they are also in their early stages of development. A recent estimate suggests that "multi-function robots" will take at least 10 years to become widely available on the market (Hennala et al. 2017). In any case, the most direct contribution of robotic technology is likely to be their function as technological aids, in maintaining the functional capacities of residents. In addition to robots being physical aids, there is an interest towards social robots among people with memory diseases and their caregivers. Social robots could give reminders or suggestions on activities, and in this way, they could assist people with dementing illnesses in their daily life and to maintain their sense of autonomy (Wang et al. 2017).

\section{Peer comparison}

Pirhonen et al. (2016) introduced the concept of ability others to capture community-dwelling nonagenarians' way of boosting their sense of autonomy by comparing their situation with those aged peers who have already been institutionalized. The residents in AL were observed to continue with the strategy, comparing their situation with others inside 
the care facility (Pirhonen and Pietilä 2016). Technological aids can also be relevant to comparisons with peers (say, my monitored number of steps taken today may be low, but still higher than Seppo's next door). Comparisons with machines are also possible: it may be linked to one's selfesteem (and indirectly to one's sense of autonomy) that one expects to fare better than a machine in what she/he does. A shoemaker's pride in making shoes may partly be because she/he does it better than other shoemakers but also because she/he does it better than automated shoe factories (for a philosophical debate on whether comparisons with machines in this way make sense, see Ikäheimo and Laitinen 2010).

\section{Potential-based sense of autonomy}

The residents were observed to talk about various things they could do if they wanted to; however, they tended to postpone the actualization of the doings to a non-specific time in the future (Pirhonen and Pietilä 2016). Johan, a resident, stated that there was a great outdoor recreational area near the AL; however, he had not been there yet. Anna, another resident, related that she could always enjoy some fresh air on a beautiful balcony; however, she had not done it yet. Hanna said that she had a cell phone to call her son but had not done so, although she had lived at the AL for 8 months. Helena, who was suffering from a somatic illness, had been given the right to take a wheelchair-accessible taxi at the cost of a bus ticket due to her illness. She said she could take a taxi and visit her friends around the town whenever she wanted to but had not done that yet. This kind of "yet" talk was common in the interviews, and it seemed that postponing accessible things to the future was a way for the residents to sustain hope in their lives. Perkins et al. (2012) found that hope is a crucial factor in residents' ability to maintain their sense of autonomy in AL settings. Postponing pleasant events creates positive future expectations. Without future expectations, a human being may be seen as a mere shadow of her/his potential. In addition to helping older persons achieve their goals, robots can reinforce the hope that the aged can do pleasant things in the future. Thus, robots may work as extensions of older persons' functional abilities, both concrete and potential (e.g., exoskeletons or robot wheelchairs enabling moving around and taking part in one's favorite hobbies, even in modified forms).

Another perspective to the potential-based sense of autonomy is that the use of robots in itself may make residents feel more connected to society. Melkas et al. (2020) found that residents in care homes felt that they could hold on to the present digital era and participate in society by using robots that were perceived as "technology of the future."

The appeal to potentials in the absence of actualizations may seem like a wrong kind of rationalization and selfdeception. Perhaps what is at stake is that they have lost their abilities but live in denial about them? In some cases, they may be doing so. A more realistic coping strategy might in such cases involve lowering the expectations (as discussed above).

However, lowered autonomy does not equal to lowered dignity. It is essential for life with dignity that even if in the final stages of life the degree of autonomy is likely to be lowered, the dignity of the person is not lowered (see Laitinen et al. 2016). In this paper, we are interested in the sense of autonomy, but it is important that even when one's degree of autonomy is lowered, and this is acknowledged by oneself and others, that one's dignity or sense of dignity (self-respect) need not be lowered at all. This is an important lesson, as this takes away motivation for self-deception: there is no necessity to retain an unrealistically high sense of autonomy if one's sense of dignity and sense of autonomy are successfully uncoupled. For instance, a robot that transported a person by carrying her/him like a baby, or a robot pet that encouraged an older person to interact with it like with a child, could affect the older person's dignity (Sharkey 2014). Or, if a robot treats an older person impersonally, without knowing her/his name or preferences, this would likely affect her feelings of dignity negatively. At the same time, a robot could also keep up the dignity of an older person if it helped her to dress up and groom herself in an appropriate way, or if the robot utilized stored knowledge on older person's previous life and preferences or improved their control over the environment (Sharkey 2014).

\section{Discussion}

From the philosophical point of view, a fully capable individual is, first, an autonomous "decider" if she/he can freely make up her/his mind (without compulsions, obsessions, or deteriorated mental powers) and be granted the opportunity to do so (without paternalism, manipulation, or domination). Second, a fully capable individual is an autonomous "agent" if she/he can freely carry out her/his decisions. A fully capable individual, then, may not need any interactive support, coping mechanisms, or shifting attention from actuality to potentiality. One distinct advantage of robots is their ability to sustain the capacities of an individual to be an autonomous decider or agent-one who does not need any of the three strategies to maintain her/his sense of autonomy. However, age-based changes in an individual's functional capacity may result in a situation where the three strategies are needed, and robots possess the potential to help. Of course, robots may not only sustain and create capacities but also, in worst cases, reduce or eliminate them, which illustrates the need for careful ethical considerations when designing and using them. 
Based on this study, robots could strengthen the sense of autonomy in older persons residing in AL facilities in multiple ways. The interaction-based sense of autonomy can be supported by different kinds of robots that could widen the residents' space of daily movements. In addition to concrete help, assistive robots can make residents feel less dependent on the staff and formal care. Social robots can in principle even become "allies" of the residents, and their presence per se has been found to have a positive effect on older people (Sorell and Draper 2014). Telepresence robots, on the other hand, may bring relatives and friends outside the facility closer and thus empower the residents and make them feel more autonomous. The coping-based sense of autonomy can be strengthened by assistive robots, such as exoskeletons, which can sustain the residents' capacities. Robots may be pictured as hi-tech aids to older people, helping them accomplish multiple tasks that would otherwise pose severe challenges to their functional abilities. With a little help from a robot, the residents may be able to carry on with their life-long hobbies for extended periods or perhaps even start new ones. Regarding the potential-based sense of autonomy, robots can help older persons maintain and even create future expectations, since they can work as guarantors of their future actions: if an older person loses her/his ability to achieve a goal independently, a robot may work as an extension of her/his agency and secure the accomplishment in the future (c.f. Perkins et al. 2012; Pirhonen and Pietilä 2016). Robots may thus create capabilities for the residents.

In connection with the sense of autonomy of older persons residing in AL facilities, robotics has several serious limitations. The majority of residents suffer from dementing illnesses today (Matthews and Dening 2002; Noro and Alastalo 2014; Wolinsky et al. 1993). The more severe the cognitive impairment is, the fewer the chances for a person to use robots in the first place, and the vast majority of residents will eventually lose the ability to make use of robotics. This does not mean that robots will have no part to play in care for people with dementing illnesses; it rather means that we need to understand the use of care robots in their socio-historical context. For example, animal-shaped therapeutic robots have been found to both comfort and stimulate people suffering from dementing illnesses (Cesta et al. 2016; Gustafsson et al. 2015). The role of nursing staff also differs; their role in robot use is more prominent in care for people with dementing illnesses. An important issue to consider is that nursing staff are given resources for appropriate robotics, training in using them and training in giving guidance to others. Studying robots' capabilities to maintain the sense of autonomy of people with cognitive illnesses is not an easy task; however, it could perhaps be carried out by observing human-robot interaction in these cases. Kontos (2005) who has studied the agency of people with Alzheimer's disease argues that the body is an active, communicative agent, imbued with its own wisdom, intentionality, and purposefulness. Kontos' idea could lead the way for future research on the robot-assisted sense of (bodily) autonomy of people with cognitive illnesses.

Dementing illnesses bring forth other autonomy-related ethical problems, such as deception and loss of privacy. As noted previously, the creator of Care-O-bot claims that the latest version is "as courteous, friendly, and affable as a gentleman." People tend to anthropomorphize objects and imagine that they are capable of more than they actually are. Human-like and animal-like appearances can mislead older people into thinking that robots are more capable than is actually the case. For example, in Hutson et al.'s (2011) empirical study, the participants compared the animal-type robots with house pets and expected them to behave like real animals. The participants also reported feeling responsible for robot animals' welfare (Hutson et al. 2011). Their appearance and behavior can lead people to think that they could form adequate replacements for human or animal companionship and interaction. If manufacturers design robots that resemble humans and behave like humans, people with dementia may not always be able to distinguish them from real humans. Many researchers primarily perceive this as deception (Blackford 2012; Coeckelbergh 2012; also see Vandemeulebroucke et al. 2017b). Others, however, hold that deception is not necessarily a bad thing if it benefits the person at stake (Sharkey and Sharkey 2011). For example, Paro- the seal-like robot—has been found to relieve older people's loneliness (Robinson et al. 2013); hence, pragmatically, it would be right to provide lonely older persons with Paros. From the philosophical point of view, deception can directly undermine autonomy. One's responsibility for one's autonomous choices is reduced if one is manipulated into making a decision or accepting a decision made by others.

Researchers have also brought up the issue of privacy in connection with autonomy, since people in general and people with dementia in particular may not necessarily understand that some robots may collect information about them (Sharkey and Sharkey 2012). Surveillance can directly undermine autonomy as readily as does deception above. Therefore, thorough ethical deliberation and broad consensus on robot data collection, data storage, and criteria for informed consent are needed before robots are widely introduced in elderly care facilities (see Vandemeulebroucke et al. 2017b).

There are some limitations regarding this research. In this study, actual robots were not tested or used, but the idea of considering the potential impacts of robots was born after the original study on resident autonomy was conducted. Therefore, this study does not reflect on residents' views on care robots, but is a future-oriented theoretical paper. However, the study explored robots' future potential in light of research literature on care robotics and empirical research 
on resident autonomy. Highly advanced robots do exist (see, e.g., https://www.bostondynamics.com/); however, they are still being tested in laboratories and are far too expensive to be used for the everyday routine life of ordinary people. Bedaf et al. (2015) were able to identify only six commercial robots among 107 products for the elderly in 2015. Genuinely social and intelligent robots to assist people with their personal needs always seem to appear on the market "in a few years' time." In the meantime, as far as users' needs and robots' sensible tasks conducive to each environment are concerned, there are many robots of other types available with promising potential and perhaps fewer risks. To be able to observe autonomous robots interacting with older persons in real life, we need to theorize and "potentialize"; this way, we will be better prepared for the future. It is undoubtedly more sensible and responsible to adjust care robotics to practices and procedures of the elderly care rather than vice versa. It would make an interesting follow-up study to discuss our ideas presented in this paper with AL residents to see how they perceive the results.

Another limitation is that an ethnographical research frame may be considered somewhat problematic regarding generalizations of research results. For example, autonomy is a universal value, yet it may be perceived differently in different cultures. This calls for multicultural research on robot-related autonomy in the future.

A preventive approach is also necessary. Providing sufficient rehabilitation and physical exercise to maintain and strengthen residents' remaining abilities with the help of robots could improve opportunities for all three types of sense of autonomy. This is essential for nursing staff and management as well as residents' relatives. In general, there should be a network behind the use of robots so that it does not take place in a "vacuum."

\section{Conclusions}

Robots seem to be an "evolving species." Compared to living organisms evolving slowly over time, they evolve quickly. Robot technology proceeds by leaps and bounds in tandem with the development of artificial intelligence (AI), moving from factory floors to public life (Vandemeulebroucke et al. 2017b). They have evolved from being a tool in a factory to an aide at home and from an aide at home to a butler-they are now even evolving from a butler to a friend. It is very difficult to envision the variety of implications of future robots' introduction in care settings. As this paper shows, robots may strengthen the sense of autonomy of older persons residing in AL; however, they may simultaneously pose a threat. Therefore, now it is time to discuss whether robots are welcomed in care, and if they are, how, for whom, and in what areas. Philosophers and ethicists, as well as care professionals and officials, need to join technology developers to develop novel guidelines for future care of older people.

Acknowledgements This research was supported by the Strategic Research Council at the Academy of Finland (Project name: "Robots and the Future of Welfare Services" [ROSE], decision numbers 292980 and 314180), and the LUT Research Platform on Smart Services for Digitalisation (DIGI-USER).

Open Access This article is licensed under a Creative Commons Attribution 4.0 International License, which permits use, sharing, adaptation, distribution and reproduction in any medium or format, as long as you give appropriate credit to the original author(s) and the source, provide a link to the Creative Commons licence, and indicate if changes were made. The images or other third party material in this article are included in the article's Creative Commons licence, unless indicated otherwise in a credit line to the material. If material is not included in the article's Creative Commons licence and your intended use is not permitted by statutory regulation or exceeds the permitted use, you will need to obtain permission directly from the copyright holder. To view a copy of this licence, visit http://creativecommons.org/licenses/by/4.0/.

\section{References}

Aaltonen, I., Niemelä, M., \& Tammela, A. (2017). Please call me?: Calling practices with telepresence robots for the elderly. Proceedings of the Companion of the 2017 ACM/IEEE International Conference on Human-Robot Interaction, Vienna, Austria, pp. 55-56.

Agich, G. (2003). Dependence and autonomy in old age. An ethical framework for long-term care. Cambridge: Cambridge University Press.

Anderson, J., \& Honneth, A. (2005). Autonomy, vulnerability, recognition, and justice. In J. Christman \& J. Anderson (Eds.), Autonomy and the challenges to liberalism: New essays (pp. 127-149). New York: Cambridge University Press.

Anttonen, A., \& Häikiö, L. (2011). Care 'going market': Finnish elderly-care policies in transition. Nordic Journal of Social Research, 2, 71-90.

Atkins, K. (2006). Autonomy and autonomy competencies: A practical and relational approach. Nursing Philosophy, 7(4), 205-215.

Ball, M. M., Perkins, M. M., Whittington, F. J., Connell, B. R., Hollingsworth, C., King, S. V., et al. (2004). Managing decline in assisted living: The key to aging in place. The Journals of Gerontology Series B: Psychological Sciences and Social Sciences, 59(4), 202-212.

Bedaf, S., Gelderblom, G. J., \& de Witte, L. (2015). Overview and categorization of robots supporting independent living of elderly people: What activities do they support and how far have they developed. Assistive Technology, 27(2), 88-100.

Benzidia, S., Ageron, B., Bentahar, O., \& Husson, J. (2018). Investigating automation and AGV in healthcare logistics: A case study based approach. International Journal of Logistics Research and Applications, 22(3), 273-293.

Blackford, R. (2012). Robots and reality: A reply to Robert Sparrow. Ethics and Information Technology, 14(1), 41-51.

Brooker, D. (2004). What is person-centered care in dementia? Reviews in Clinical Gerontology, 13, 215-222.

Brownie, S., \& Nancarrow, S. (2013). Effects of person-centered care on residents and staff in aged-care facilities: A systematic review. Clinical Interventions in Aging, 8, 1-10. 
Bush, E. (2001). The use of human touch to improve the well-being of older adults a holistic nursing intervention. Journal of Holistic Nursing, 19(3), 256-270.

Collopy, B. J. (1988). Autonomy in long-term care: Some crucial distinctions. The Gerontologist, 28(Suppl), 10-17.

Cesta, A., Cortellessa, G., Orlandini, A., \& Tiberio, L. (2016). Longterm evaluation of a telepresence robot for the elderly: Methodology and ecological case study. International Journal of Social Robotics, 8(3), 421-441.

Chapin, R., \& Dobbs-Kepper, D. (2001). Aging in place in assisted living: Philosophy versus policy. The Gerontologist, 41(1), 43-50.

Christensen, K., Doblhammer, G., Rau, R., \& Vaupel, J. W. (2009). Ageing populations: The challenges ahead. The Lancet, 374(9696), 1196-1208.

Christman, J. (2014). Relational autonomy and the social dynamics of paternalism. Ethical Theory and Moral Practice, 17(3), 369-382.

Coeckelbergh, M. (2012). Are emotional robots deceptive? IEEE Transactions on Affective Computing, 3(4), 388-393.

Dick, H. V. (2014). "Every time you deal with a death you think, 'One day'...": The emotional and spiritual effects of dealing with aging, dying, and death for staff in a residential aged care facility. Journal of Religion, Spirituality \& Aging, 26(2-3), 173-185.

Eyers, I., Arber, S., Luff, R., Young, E., \& Ellmers, T. (2012). Rhetoric and reality of daily life in English care homes: the role of organised activities. International Journal of Ageing and Later Life, 7(1), 53-78.

Freund, A. M., \& Baltes, P. B. (1998). Selection, optimization, and compensation as strategies of life management: Correlations with subjective indicators of successful aging. Psychology and Aging, 13(4), 531-543.

Garner, T. A., Powell, W. A., \& Carr, V. (2016). Virtual carers for the elderly: A case study review of ethical responsibilities. Digital Health, 2, 1-14.

Giannakouris, K. (2008). Ageing characterises the demographic perspectives of the European societies. Statistics in Focus, 72, 1-12.

Goeldner, M., Herstatt, C., \& Tietze, F. (2015). The emergence of care robotics-A patent and publication analysis. Technological Forecasting and Social Change, 92, 115-131.

Goher, K. M. (2016). A reconfigurable wheelchair for mobility and rehabilitation: Design and development. Cogent Engineering, 3(1), 1261502. https://doi.org/10.1080/23311916.2016.1261502.

Government of British Columbia. (2018). Considering seniors' assisted living. Retrieved March 3, 2019, from http://www2.gov.bc.ca/gov/ content/health/accessing-health-care/finding-assisted-living-orresidential-care/assisted-living-residences/seniors-assisted-livin g/considering-seniors-assisted-living.

Gustafsson, C., Svanberg, C., \& Müllersdorf, M. (2015). Using a robotic cat in dementia care: A pilot study. Journal of Gerontological Nursing, 41(10), 46-56.

Hennala, L., Koistinen, P., Kyrki, V., Kämäräinen, J-K., Laitinen, A., Lanne, M., Lehtinen, H., Leminen, S., Melkas, H., Niemelä, M., Parviainen, J., Pekkarinen, S., Pieters, R., Pirhonen, J., Ruohomäki, I., Särkikoski, T., Tuisku, O., Tuominen, K., Turja, T., \& Van Aerschot, L. (2017). Robotics in care services: A finnish roadmap. Retrieved October 9, 2019, from http://roseproject.aalto .fi/images/publications/Roadmap-final02062017.pdf.

Hsieh, H. F., \& Shannon, S. E. (2005). Three approaches to qualitative content analysis. Qualitative Health Research, 15(9), 1277-1288.

Hutson, S., Lim, S. L., Bentley, P. J., Bianchi-Berthouze, N., \& Bowling, A. (2011). Investigating the suitability of social robots for the wellbeing of the elderly. In S. D'Mello, A. Graesser, B. Schuller, \& J. C. Martin (Eds.), Affective computing and intelligent interaction. ACII 2011. Lecture notes in computer science (Vol. 6974, pp. 578-587). Berlin: Springer.

Ikäheimo, H., \& Laitinen, A. (2010). Esteem for contributions to the common good: The role of personifying attitudes and instrumental value. In M. Seymour (Ed.), The plural states of recognition (pp. 98-121). New York: Palgrave MacMillan.

Kachouie, R., Sedighaedeli, S., Koshia, R., \& Chu, M. T. (2014). Socially assistive robots in elderly care: A mixed methods systematic literature review. International Journal of Human-Computer Interaction, 30(5), 369-393.

Karunarathne, D., Morales, Y., Nomura, T., Kanda, T., \& Ishiguro, H. (2018). Will older adults accept a humanoid robot as a walking partner? International Journal of Social Robotics, 11(2), 343-358.

Koceski, S., \& Koceska, N. (2016). Evaluation of an assistive telepresence robot for elderly healthcare. Journal of Medical Systems, 40, 121. https://doi.org/10.1007/s10916-016-0481-x.

Kontos, P. C. (2004). Ethnographic reflections on selfhood, embodiment and Alzheimer's disease. Ageing \& Society, 24(6), 829-849.

Kontos, P. C. (2005). Embodied selfhood in Alzheimer's disease: Rethinking person-centred care. Dementia, 4(4), 553-570.

Laitinen, A., Niemelä, M., \& Pirhonen, J. (2016). Social robotics, elderly care, and human dignity: A recognition theoretical approach. In J. Seibt, M. Nørskov, \& S. Andersen (Eds.), What social robots can and should do (pp. 155-163). Washington, DC: IOS Press.

Lidz, C. W., Fischer, L., \& Arnold, R. M. (1992). The erosion of autonomy in long-term care. New York: Oxford University Press.

Lloyd, L., Calnan, M., Cameron, A., Seymour, J., \& Smith, R. (2014). Identity in the fourth age: Perseverance, adaptation and maintaining dignity. Ageing \& Society, 34(1), 1-19.

Mackenzie, C., \& Stoljar, N. (Eds.). (2000). Relational autonomy: Feminist perspectives on automony, agency, and the social self. Oxford: Oxford University Press.

Matthews, F. E., \& Dening, T. (2002). Prevalence of dementia in institutional care. The Lancet, 360(9328), 225-226.

Melkas, H., Hennala, L., Pekkarinen, S., \& Kyrki, V. (2020). Impacts of robot implementation on care personnel and clients in elderly-care institutions. International Journal of Medical Informatics. https ://doi.org/10.1016/j.ijmedinf.2019.104041.

Ministry of Social Affairs and Health. (2018). Quality recommendation to guarantee a good quality of life and improved services for older persons 2017-2019. Publications of the Ministry of Social Affairs and Health 1/2018, Helsinki. Retrieved March 4, 2019, from http://urn.fi/URN:ISBN:978-952-00-3906-6.

Mitchell, J. M., \& Kemp, B. J. (2000). Quality of life in assisted living homes a multidimensional analysis. The Journals of Gerontology Series B, 55(2), 117-127.

Mitzner, T. L., Chen, T. L., Kemp, C. C., \& Rogers, W. A. (2014). Identifying the potential for robotics to assist older adults in different living environments. International Journal of Social Robotics, 6(2), 213-227.

Morgan, L. A., Rubinstein, R. L., Frankowski, A. C., Perez, R., Roth, E. G., Peeples, A. D., et al. (2014). The facade of stability in assisted living. The Journals of Gerontology Series B, 69(3), 431-441.

Morgan, S., \& Yoder, L. H. (2012). A concept analysis of personcentered care. Journal of Holistic Nursing, 30(1), 6-15.

Moyle, W., Jones, C., Cooke, M., O'Dwyer, S., Sung, B., \& Drummond, S. (2014). Connecting the person with dementia and family: A feasibility study of a telepresence robot. BMC Geriatrics, 14(1), 7

Niemelä, M., \& Melkas, H. (2019). Robots as social and physical assistants in elderly care. In M. Toivonen \& E. Saari (Eds.), Human-centered digitalization and services (pp. 177-197). Singapore: Springer.

Niemelä, M., van Aerschot, L., Tammela, A., Aaltonen, I., \& Lammi, H. (2019). Towards ethical guidelines of using telepresence robots in residential care. International Journal of Social Robotics. https://doi.org/10.1007/s12369-019-00529-8. 
Noro, A., \& Alastalo, H. (Eds.). (2014). Vanhuspalvelulain 980/2012 toimeenpanon seuranta. Tilanne ennen lain voimaantuloa vuonna 2013. [Implementation of the Act for Elderly Care and Services in Finland (980/2012) - The situation before the law came into force in 2013]. Tampere: Juvenes Print-Suomen Yliopistopaino Oy.

Pekkarinen, S., \& Melkas, H. (2017). Digitalisation in health care and elderly care services: From potholes to innovation opportunities. International Journal of Information Systems and Social Change, 8(1), 24-45.

Pekkarinen, S., Melkas, H., Kuosmanen, P., Karisto, A., \& Valve, R. (2013). Towards a more social orientation in Gerontechnology: Case study of the "Reminiscence Stick". Journal of Technology in Human Services, 31(4), 337-354.

Perkins, M., Ball, M. M., Whittington, F. J., \& Hollingsworth, C. (2012). Relational autonomy in assisted living: A focus on diverse care settings for older adults. Journal of Aging Studies, 26(2), $214-225$

Pirhonen, J. (2017). Good human life in assisted living for older people: What the residents are able to do and be. Tampere: Suomen Yliopistopaino-Juvenes Print Oy.

Pirhonen, J., Ojala, H., Lumme-Sandt, K., \& Pietilä, I. (2016). Old but not that old: Finnish community dwelling people aged $90+$ negotiating their autonomy. Ageing \& Society, 36(8), 1625-1644.

Pirhonen, J., \& Pietilä, I. (2016). Perceived resident-facility fit and sense of control in assisted living. Journal of Aging Studies, 38, $47-56$.

Raz, J. (1986). The morality of freedom. Oxford: Oxford University Press.

Robertson, J. (2007). Robo sapiens Japanicus: Humanoid robots and the posthuman family. Critical Asian Studies, 39(3), 369-398.

Robinson, H., MacDonald, B., \& Broadbent, E. (2014). The role of healthcare robots for older people at home: A review. International Journal of Social Robotics, 6(4), 575-591.

Robinson, H., MacDonald, B., Kerse, N., \& Broadbent, E. (2013). The psychosocial effects of a companion robot: A randomized controlled trial. Journal of the American Medical Directors Association, 14(9), 661-667.

Roger, K., Guse, L., Mordoch, E., \& Osterreicher, A. (2012). Social commitment robots and dementia. Canadian Journal of Aging, 31(1), 87-94.

Roth, E. G., \& Eckert, J. K. (2011). The vernacular landscape of assisted living. Journal of Aging Studies, 25(3), 215-224.

Sale, P., Franceschini, M., Waldner, A., \& Hesse, S. (2012). Use of the robot assisted gait therapy in rehabilitation of patients with stroke and spinal cord injury. European Journal of Physical and Rehabilitation Medicine, 48(1), 111-121.

Sharkey, A. (2014). Robots and human dignity: A consideration of the effects of robot care on the dignity of older people. Ethics and Information Technology, 16(1), 63-75.

Sharkey, A., \& Sharkey, N. (2011). Children, the elderly, and interactive robots: Anthropomorphism and deception in robot care companionship. IEEE Robotics and Automation Magazine, 18(1), 32-38.

Sharkey, A., \& Sharkey, N. (2012). Granny and the robots: Ethical issues in robot care for the elderly. Ethics and Information Technology, 14(1), 27-40.

Sherwin, S., \& Winsby, M. (2010). A relational perspective on autonomy for older adults residing in nursing homes. Health Expectations, 14(2), 182-190.

Shiomi, M., Iio, T., Kamei, K., Sharma, C., \& Hagita, N. (2015). Effectiveness of social behaviors for autonomous wheelchair robot to support elderly people in Japan. PLoS ONE, 10(5), e0128031. https://doi.org/10.1371/journal.pone.0128031.
Smarr, C.-A., Mitzner, T. L., Beer, J. M., Prakash, A., Chen, T. L., Kemp, C. C., et al. (2014). Domestic robots for older adults: Attitudes, preferences, and potential. International Journal of Social Robotics, 6(2), 229-247.

Sorell, T., \& Draper, H. (2014). Robot carers, ethics, and older people. Ethics and Information Technology, 16, 183-195.

Sparrow, L., \& Sparrow, R. (2006). In the hands of machines? The future of aged care. Minds and Machines, 16(2), 141-161.

Street, D., Burge, S., Quadagno, J., \& Barrett, A. (2007). The salience of social relationships for resident well-being in assisted living. The Journals of Gerontology Series B, 62(2), 129-134.

Thurmond, V. A. (2001). The point of triangulation. Journal of Nursing Scholarship, 33(3), 253-258.

Turja, T., Rantanen, T., \& Oksanen, A. (2017). Robot use self-efficacy in healthcare work (RUSH): Development and validation of a new measure. AI \& Society, 34(1), 137-143.

Turkle, S. (2011). Alone together: Why we expect more from technology and less from each other. New York: Basic Books.

van Wynsberghe, A. (2013). Designing robots for care: Care centered value-sensitive design. Science and Engineering Ethics, 19(2), 407-433.

Vandemeulebroucke, T., Dierckx de Casterlé, B., \& Gastmans, C. (2017a). The use of robots in aged care: A systematic review of argument-based ethics literature. Archives of Gerontology and Geriatrics, 74, 15-25.

Vandemeulebroucke, T., Dierckx de Casterlé, B., \& Gastmans, C. (2017b). How do older adults experience and perceive socially assistive robots in aged care: A systematic review of qualitative evidence. Aging \& Mental Health, 22(2), 149-167.

Wada, K., \& Shibata, T. (2007). Living with seal robots-Its sociopsychological and physiological influences on the elderly at a care house. IEEE Transactions on Robotics, 23(5), 972-980.

Wang, R. H., Sudhama, A., Begum, M., Huq, R., \& Mihailidis, A. (2017). Robots to assist daily activities: Views of older adults with Alzheimer's disease and their caregivers. International Psychogeriatrics, 29(1), 67-79.

Werner, C., Ullrich, P., Geravand, M., Peer, A., Bauer, J. M., \& Hauer, K. (2018). A systematic review of study results reported for the evaluation of robotic rollators from the perspective of users. Disability and Rehabilitation Assistive Technology, 13(1), 31-39.

Wolinsky, F. D., Callahan, C. M., Fitzgerald, J. F., \& Johnson, R. J. (1993). Changes in functional status and the risks of subsequent nursing home placement and death. Journal of Gerontology, 48(3), 94-101.

Zamir, S., Hennessy, C. H., Taylor, A. H., \& Jones, R. B. (2018). Video-calls to reduce loneliness and social isolation within care environments for older people: An implementation study using collaborative action research. BMC Geriatrics, 18, 62. https://doi. org/10.1186/s12877-018-0746-y.

Zimmerman, S., Gruber-Baldini, A. L., Sloane, P. D., Eckert, J. K., Hebel, J. R., Morgan, L. A., et al. (2003). Assisted living and nursing homes: Apples and oranges? The Gerontologist, 43(2), $107-117$.

Zimmerman, S., Sloane, P. D., Eckert, J. K., Gruber-Baldini, A. L., Morgan, L. A., Hebel, J. R., et al. (2005). How good is assisted living? Findings and implications from an outcomes study. The Journals of Gerontology Series B, 60(4), 195-204.

Publisher's Note Springer Nature remains neutral with regard to jurisdictional claims in published maps and institutional affiliations. 